\title{
Sound production and associated behavior of tagged fin whales (Balaenoptera physalus) in the Southern California Bight
}

\author{
Alison K Stimpert ${ }^{1 *}$, Stacy L DeRuiter ${ }^{2,3}$, Erin A Falcone ${ }^{4}$, John Joseph ${ }^{5}$, Annie B Douglas ${ }^{4}$, David J Moretti ${ }^{6}$, \\ Ari S Friedlaender ${ }^{7,8}$, John Calambokidis ${ }^{4}$, Glenn Gailey ${ }^{4}$, Peter L Tyack ${ }^{9}$ and Jeremy A Goldbogen ${ }^{10}$
}

\begin{abstract}
Background: For marine animals, acoustic communication is critical for many life functions, yet individual calling behavior is poorly understood for most large whale species. These topics are important for understanding whale social behavior and can also serve as a baseline for behavioral studies assessing whale response to disturbance. Using a new technique for identifying the calling individual, we measured body orientation, dive behavior, and surface social behavior in relation to call production for tagged fin whales in Southern California.

Results: Behavioral metrics associated with elevated call rates included shallow maximum dive depths (10-15 m), little body movement, negative pitch in body orientation, and moderate body roll. Calling whales were also more likely to be traveling than milling, in groups rather than solitary, and without change in group size compared to non-calling whales.

Conclusions: These are the first descriptions of body posture and depths at which fin whales are most likely to call, and some possible sound propagation and/or anatomical reasons for these results are considered. The call behavior characterizations presented here will help in predicting calling behavior from surface behavior, informing interpretation of passive acoustic data, and determining the effects of anthropogenic sound on whales in Southern California.
\end{abstract}

Keywords: Fin whale, Balaenoptera physalus, Acoustic behavior, Sound production, Biologging, DTAG

\section{Background}

Sound production is important for life history functions in many species. Terrestrial species known for their acoustic behavior include songbirds, where complex vocal displays are used for sexual advertisement [1], vervet monkeys, where categorical alarm calls help alert conspecifics to the presence of various predators [2], and bats, which use echolocation to navigate through their nighttime environment and to find highly mobile prey in three-dimensional space [3]. In the marine environment, the use of sound may be even more advantageous because sound propagates better than light through water. Toothed whales (odontocetes), like bats, rely on

\footnotetext{
*Correspondence: astimpert@mlml.calstate.edu

1 Vertebrate Ecology Laboratory, Moss Landing Marine Laboratories, Moss Landing, CA, USA

Full list of author information is available at the end of the article
}

echolocation for navigation and foraging [4], and most marine mammals produce sound for social and communicative purposes. Of all the baleen whales (mysticetes), humpback whale acoustics have been the best studied, and this species is known for its song displays, which are among the most complex in the animal kingdom [5]. Singing whales on their winter breeding grounds are often solitary, and during audio recordings can simultaneously be visually observed in the clear tropical waters they inhabit during this period. Thus, songs can be ascribed to individuals and linked to age, sex, and concurrent behavior, such as the singer remaining stationary, pitched down, and at a relatively shallow depth [6]. However, when soniferous whales are farther offshore, in rough or murky waters, in social groups, or mobile, this observational method of studying acoustic behavior is no longer feasible. 
One method of studying sound production behavior for less accessible marine species is passive acoustic monitoring (PAM). The sounds baleen whales produce are some of the loudest in the ocean, and their low frequencies travel long distances [7], which makes PAM an appropriate tool for monitoring distributions of whales over a large area. Calling blue and fin whales (Balaenoptera musculus and Balaenoptera physalus, respectively) have been detected hundreds of kilometers away [8] and their movements relative to one another tracked (through localization on hydrophone or seismometer arrays) based on differences in call character [9]. Seasonal patterns of distribution and large-scale movements of populations of these species have been studied using acoustic activity [10,11], and general call function can be inferred from differential representation of call types during different times of year $[12,13]$. An important new application of PAM is to generate estimates of distribution and abundance of populations. Marques et al. [14] review new approaches to solve this problem, which generally rely upon estimates of call rates of individuals and of the probability of detecting a call as a function of range from the receiver. Knowing the depth of the caller can be important for modeling these detection ranges, and can in some cases be calculated from multi-hydrophone passive acoustic arrays [15]. Unfortunately, conclusions about social context or dive behavior of the calling animals in these situations can only be drawn on a relatively coarse scale, as it is not generally possible to record the fine-scale movements or social context of a calling whale during call production from a remote location. This is because it is particularly difficult to use localization to identify an individual caller when it is in an interacting group, as localization accuracy is not always as fine as inter-animal separations [16].

In recent years, developments in biologging technology have allowed for the collection of fine-scale movement data during calling from some baleen whale species. In some cases, assumptions have been made that certain sounds recorded on acoustic and movement recording tags were produced by the tagged animal itself, which allows concurrent behavior, including call depths, to be described. Humpback whales have been shown producing unique clicking [17] and repetitive burst sounds [18] during nighttime foraging at depth, right whales have been shown to have calling rates that are highest during periods of surface activity or travel [19], Antarctic minke whales produced bio-duck sounds while near the surface [20], and blue whales were shown to produce calls at relatively shallow depths $(20-30 \mathrm{~m})$ and without much movement [21, 22]. In most of the aforementioned cases, animals were either alone, or assumptions were made based on the acoustic properties of the sounds to assign caller identity to the tagged animal. But given that baleen whales can greatly vary their sound source level [23], even these techniques may not always be accurate [24]. Also, some of the most interesting social behavior likely happens when animals are in close-knit groups, making restricting datasets to solo animals (to ensure the caller is the tagged animal) limiting. In short, describing the concurrent behavior of calling individuals in any baleen whale species is generally problematic, and to date there have been no studies characterizing the fine-scale behavioral context of calling in fin whales using any method.

A recent study by Goldbogen et al. [25] developed a new method for confirming the identity of the calling animal in tag datasets using high-sample rate accelerometry synchronized with hydrophone acoustic data. This method uses call signatures in the raw accelerometer data that are thought to result from the animal's body vibrations as the call is produced. With current technology, the technique is applicable only to very low-frequency callers: blue and fin whales.

Current knowledge of fin whale calling has been gathered on a coarse scale through remote data collection such as bottom-mounted recorders, towed hydrophone arrays, and hydrophone recordings concurrent with visual observations. Fin whales are known to produce several call types, varying across geographic location, population, and season, some of which are among the lowest-frequency calls in the ocean. The most common vocalization is a slightly downswept 30 to $20 \mathrm{~Hz}$ pulse of approximately $1 \mathrm{~s}$ in duration, found worldwide [10, 12, 26]. Another type of call that is less frequently recorded in the North Pacific is a higher-frequency 75 to $40 \mathrm{~Hz}$ downsweep, occurring mostly in summer [27], and which may be associated with feeding [12]. Less common call types have also been recorded and described in the North Atlantic [28, 29]. The $20 \mathrm{~Hz}$ fin whale call is thought to be used in social contexts, or as a long distance contact call [12, 30], and has also been observed as part of counter-calling behavior [9]. This call type has also been associated with song in fin whales, which has been hypothesized to be an attractant for females since, as in humpback whales, only males have been reported to sing [31]. However, there has not yet been any characterization of behavioral state and kinematic movements coincident with call production in fin whales, particularly when whales are in any kind of aggregation.

Here, we describe the swimming behavior and social context corresponding with calling in individual tagged fin whales in the summer and fall in the Southern California Bight. We first report common depths and body orientations for both producing calls and receiving calls of other animals. We then apply the caller identification technique of Goldbogen et al. [25] to identify which calls (of 
any type) are produced by the tagged animal, and develop a model to describe the behaviors and social settings that best predict call production. These data will inform hypotheses about call production and call function, and will also help with interpretation of passive acoustic detections and controlled exposure experiments to understand the behavioral effects of acoustic disturbance.

\section{Methods}

Fin whales were tagged between 2010 and 2013 as part of the Southern California Behavioral Response Study (SOCAL BRS), to investigate the effects of Navy sonar on cetaceans [32]. Some of the animals included in this analysis were exposed to controlled exposures of simulated Navy sonar or pseudo-random noise, but in those cases, data from during and after the sound exposure were excluded from analysis to conservatively use only baseline (natural) behavior data (although we cannot rule out that behavior may have been influenced by tag deployment, tag attachment, or presence of research vessels during the experiment). Tag durations in Table 1 reflect these adjusted recording periods.

\section{Tag data}

Whales were instrumented with DTAGs [33], which are sound- and movement-recording tags that include hydrophones and a pressure sensor as well as tri-axial accelerometers and magnetometers. The majority of analyses presented here include data from DTAG version 3, which was used beginning in 2012. The DTAG3 accelerometers can sample at 200-500 Hz. This increased sample rate allowed us to apply the accelerometer-based method for identifying the calling animal [25]. [DTAG2 instruments were not capable of this high-rate accelerometry.] For this analysis, tag acoustic records were manually audited by experienced analysts. Before plotting, acoustic data were adjusted for measured tag sensitivity (based on laboratory calibration at $10 \mathrm{~Hz}$ to $20 \mathrm{kHz}$ ) to account for reduced hydrophone response at low frequency and the effects of the tag's analog high-pass filter [as in 25]. Data were then decimated to $600 \mathrm{~Hz}$ and a fourth-order Butterworth bandpass filter between 10 and $60 \mathrm{~Hz}$ was applied before plotting the spectrogram (Hamming window, Fast Fourier transform (FFT) size 512, 98\% overlap) and waveform. Analysts identified every call visible on the acoustic record by marking call times on the waveform plot. Synchronized raw accelerometer data were simultaneously examined, and calls were categorized as produced by the tagged whale (detected on acoustic record and at least one accelerometer axis) or produced by other whales (only detected on acoustic record). The vast majority of calls were the

Table 1 List of tagged whales

\begin{tabular}{lllll}
\hline Date & Whale ID & Tag type & $\begin{array}{l}\text { Baseline tag } \\
\text { duration (h) }\end{array}$ & $\begin{array}{l}\text { Number of calls identified } \\
\text { (produced by tagged animal) }\end{array}$ \\
\hline 8/24/2010 & bp10_236a & 2 & 2.5 & 0 \\
8/24/2010 & bp10_236b & 2 & 2.1 & 0 \\
8/27/2010 & bp10_239a & 2 & 2.8 & 0 \\
9/1/2010 & bp10_244a & 2 & 2.9 & 0 \\
9/1/2010 & bp10_244b & 2 & 2.3 & $288(\mathrm{n} / \mathrm{a})$ \\
9/2/2010 & bp10_245a & 2 & 1.0 & 0 \\
9/4/2010 & bp10_247a & 2 & 2.2 & $44(\mathrm{n} / \mathrm{a})$ \\
8/4/2012 & bp12_217a & 2 & 2.9 & 0 \\
10/20/2012 & bp12_294a & 3 & 3.1 & $372(338)$ \\
5/19/2013 & bp13_139a & 3 & 1.6 & 0 \\
8/4/2013 & bp13_216a & 3 & 2.3 & 0 \\
9/14/2013 & bp13_257a & 3 & 2.4 & 0 \\
9/14/2013 & bp13_257b & 3 & 3.0 & $33(23)$ \\
9/15/2013 & bp13_258a & 3 & 5.9 & 0 \\
9/15/2013 & bp13_258b & 3 & 5.5 & $515(419)$ \\
9/15/2013 & bp13_258c & 3 & 6.3 & $1,237(942)$ \\
9/16/2013 & bp13_259a & 3 & 2.1 & 0 \\
9/22/2013 & bp13_265a & 3 & 3.7 & 0 \\
\hline Amo & & 3.7 &
\end{tabular}

Amount of data collected for each tagged whale (in hours and number of calls identified) excluding periods during or after experimental sound exposure, but including silent control trials. No tags contained calls that only occurred during and/or after an experimental exposure period. Whale ID indicates species ('bp'), year $\left(' 10^{\prime}\right)$, Julian day of deployment ('236'), and the number deployment within that day ('a'). Tag type indicates DTAG version 2 or version 3 (version 3 included the faster sampling accelerometer sensors). 
common $20 \mathrm{~Hz}$ pulse, but all variations were marked so as to focus on the distinction between calling and noncalling behavior in general.

\section{Focal follow data}

All tagged animals were tracked at the surface during daylight hours from a 6-m rigid-hulled inflatable boat (RHIB) from the time of tag attachment until either the tag detached, light or sea conditions forced cessation of the focal follow, or the animal was lost. Focal follow data were collected every time the tagged whale surfaced, to the extent possible, and observations were labeled with the exact time at which they were made. For statistical analysis, data were analyzed in 1-min time bins, which for focal follow data were necessarily associated with the observations from the most recent prior surfacing by the tagged whale. Focal follow data were also collapsed into three simplified categories: surface movement ("directed travel" or "milling" by the tagged animal), group synchrony ("solo", "asynch", and "synch"), and group size change. For surface movement, any non-directed movements during surface intervals were combined into the milling category. Group size change was a binary variable: one in time intervals where observed group size changed, one in the time intervals preceding and following a group size change, and zero otherwise. Preceding/ following intervals were included because a) changes in group size may have actually occurred earlier than they were observed at the surface and b) we assumed that changes in call rate related to group size changes would be effective not only at the moment of change, but up to at least a minute before and afterward. The group synchrony variable attempted to address the uncertainty in defining the spatial range that might constitute a "group" in animals that range over large distances and may also be acoustically connected under water over greater distances than seem apparent from the surface. For group synchrony, "solo" indicated a solitary whale, with no other fin whales in close visual range from the focal follow RHIB. "Asynch" indicated the tagged whale was in an area with other whales, but dispersed in space and surfacing independently. "Synch" indicated the tagged whale was coordinating its surfacing behavior (both temporally and spatially) with other whales. All three of these variables applied only to behavioral state as interpreted from the surface, and though they require assumptions about behavioral state between whale surfacings, they give valuable social context to calling behavior that is not possible to obtain from tag data alone.

\section{Call rate and behavior analysis}

To statistically evaluate behavior concurrent with call production by the tagged animal, we developed a model of call rate as it related to individual and group behavior of the tagged whales. Focal follow data gave an indication of potential social context of calling, in terms of broad behavioral states (surface movement) and presence of conspecifics (group size change and group synchrony). Data extracted from the tag sensors related to the finescale movements of the tagged whale, and included pitch, roll, depth, and overall dynamic body acceleration (ODBA, [34]). Data were binned into 1-min intervals, over which the total number of calls and mean sensor value (for tag data) or most recent behavioral categories (for focal follow data) were recorded. We considered this time interval a representative compromise between focal follow and tag data, given the general level of behavioral description in our analysis. Calls were separated based on their assignment to the tagged animal or a different whale (likely one in the area, as calls from animals very far away would probably be highly attenuated by the tag's highpass filtering system, or masked by flow noise). Excluding periods without concurrent focal follow and periods during and after controlled exposure experiments resulted in 1,242 data points (1-min time bins) from nine animals for the tagged-whale call rate modeling (bp13_216a was excluded because it was in the 'solo' state the entire time).

Statistical analysis was performed in $\mathrm{R}$ version 3.1.0 [35] using the MRSea package [36] and the geepack package [37]. We expected that group size and all of the tag-based candidate predictors might have non-linear, non-monotonic relationships with call rate, so we allowed these relationships to be either linear (on the scale of the link function) or to be non-linear smooths (quadratic b-splines, except for roll). Since roll is an angular variable, and whales used the full possible range of angles, we used a cyclic cubic smooth for roll. We used SALSA (Spatially Adaptive Local Smoothing Algorithm) to determine the form of these relationships, using the Bayesian Information Criterion (BIC) to conservatively select the optimal number (1-8) and placement of internal knots [38]. (The base model for SALSA was a Poisson generalized linear model including all categorical focal follow-based predictors.) We then modeled call rate as a function of focal follow and tag covariates using Poisson Generalized Estimating Equations (GEEs, [39]), using smooth term specifications from the SALSA output for tag-derived predictors. We chose GEEs because they allow accurate estimates of population average parameters from correlated and clustered data by appropriately inflating the estimated standard errors [39]. This allowed us to account for differences between individual subjects as well as correlation over time within individuals. We used individual whale as the blocking unit for the GEE fitting, using the standard robust sandwich variance estimate for all reported results [39]. To determine which of 
the candidate predictors should be included in the final GEE model, we performed backward stepwise selection using ANOVA (sequential Wald tests) and a significance threshold of 0.05 .

\section{Acoustic analysis}

To compare our caller-identification method with some acoustic techniques used in previous research, we performed a statistical comparison of call levels (root-meansquare received levels, RMS RLs, in all cases re $1 \mu \mathrm{Pa}$ ) and signal-to-noise ratios (SNRs) between calls identified as produced by the tagged whale and those on the acoustic record, but produced by other whales.

Reported RLs of whale calls were calculated using custom software in Matlab R2014a (MathWorks, Natick, MA, USA). Calls were decimated to a sample rate of $6,000 \mathrm{~Hz}$ in this case, and low-pass filtered $\left(6^{\text {th }}\right.$-order Butterworth filter at $100 \mathrm{~Hz}$ ) before level measurement. No other signal processing was done on these samples before level measurement. The DTAG3 system has a reduced hydrophone response at low frequency, as well as an analog high-pass filter to compensate for low-frequency flow noise from recording on a swimming animal. The acoustic records in this received level analysis were not adjusted to compensate for this reduced lowfrequency sensitivity, so as to focus on level differences in whale calls rather than potentially amplified flow noise. RLs reported here are therefore only valid in comparison to each other, within a given tag (though varying ambient noise due to swim speed fluctuations may still play a role), and not to RLs reported either from tags elsewhere or to source levels calculated from passive acoustic data. Levels were calculated over the full reported signal duration calculated using a $90 \%$ energy criterion for signal duration.

Given these caveats, we tested the null hypothesis that call levels were the same between the two conditions (produced by the tagged whale, or not) by using a randomization that takes into account individual differences and temporal autocorrelation (rotation test, [40]), using as our test statistic the sum (over all whales) of the median difference in call levels (RMS RLs) and SNRs between tagged-whale and other-whale calls. The rotation test keeps all observations in a time series in their original order and rotates them randomly, rather than randomizing the order of the data points. This method gives accurate inference even in the presence of significant temporal correlation in the time series.

\section{Results}

Our dataset included 18 fin whales, 10 of which were tagged with a DTAG3 with high-resolution accelerometry, used to identify calls produced by the tagged animal
(Table 1). Six (33\%) of the acoustic records of these 18 tags contained calls. Of the four of those tags for which we could identify the calls produced by the tagged animal (DTAG3), 1,722 tagged-animal calls were recorded over the $17.9 \mathrm{~h}$ data collection period. Call times for these animals are included in Additional files (1, 2, 3, 4).

\section{Dive behavior during calling}

Figure 1 shows four representative dive profiles of tagged fin whales, both containing calls and not containing calls. Panels (a) and (c) both show a common pattern for tags containing calls, in which the tagged animal made repetitive U-shaped dives to approximately $15-20 \mathrm{~m}$, and the majority of calls were recorded when at this depth, though the identity of the calling whale in panel (a) could not be verified because it is from a record without fast accelerometry. Panel (b) shows a deeper diving, likely feeding animal for comparison. Panel (d) shows the dive profile of an animal in the same area as that in panel (c), but without any calls recorded. This animal dove to similar depths, but its dives were shorter in duration and less stereotyped than those of the calling animal. This pattern is reinforced in Figure 2. Calling animals dove deeper but for shorter durations when not calling, while still generally maintaining shallow depths. In fact dives containing calls were among the shallowest and longest of any dives in the dataset (Figure 2).

\section{Call rate modeling}

To statistically test for which behaviors were associated with call production, we used only the subset of data that included synchronous, high-resolution accelerometer data to identify the calls produced by the tagged animal. These data are shown in Figure 3 and include all time periods that contained both focal follow and tag data when calls were confirmed to have been produced by the tagged whale. For the model, the sample size was relatively small, including nine tag deployment records (bp13_216a was excluded because it was in the 'solo' state the entire time), four of which contained calls [one of those four (bp13_257b) had very few calls recorded (see Table 1)].

The GEE results confirmed the trends identified by initial dive behavior analysis. Figure 4 shows call rates by behavioral state or tag variable, taking into consideration all tagged whales in the dataset. The best GEE model included depth, pitch, ODBA, roll, surface movement, group size, and group composition change as predictors $(p<0.05$ in all cases). Predicted call rate was highest at a relatively shallow depth value (10-15 m), zero to little body movement (ODBA $\sim 0 \mathrm{~m} / \mathrm{s} / \mathrm{s}$ ), and a downwardfacing body orientation (approximately, $-30^{\circ}$ pitch) (Figure 4). Animals were also more likely to be exhibiting 


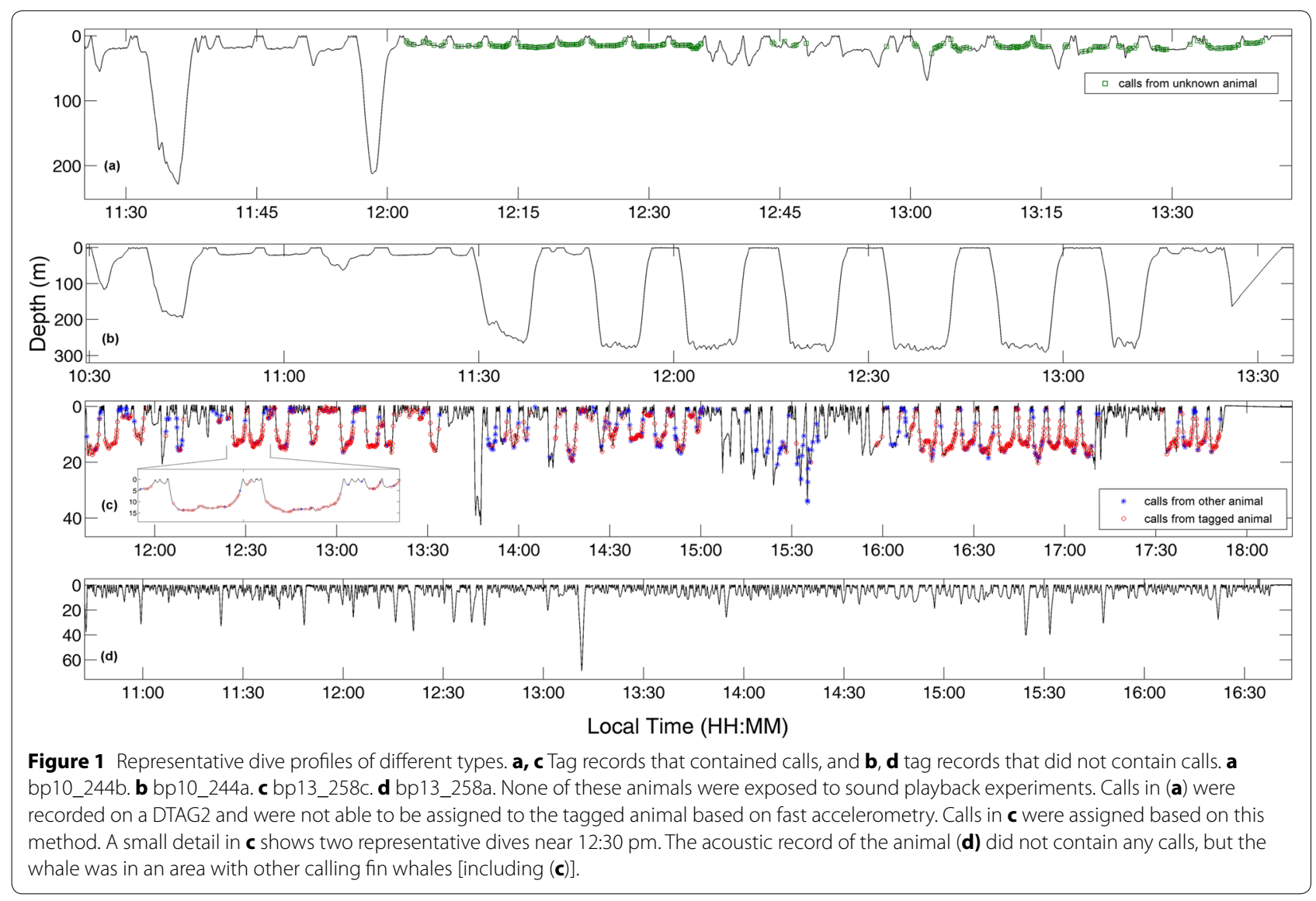

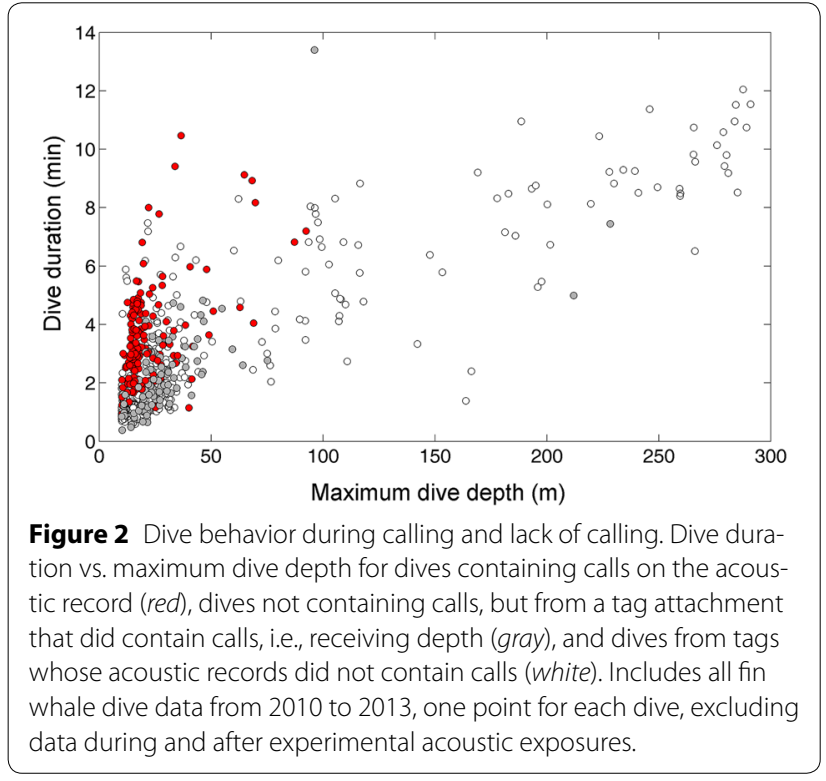

directed travel than staying in one location. Call rates were also highest at higher values of roll, but this was based on a smaller number of observations at those extreme values.

\section{Identifying callers}

Acoustic comparisons of calls identified as produced by the tagged whale (using the accelerometer method) and those produced by other whales did show differences in RMS RLs and SNRs, with both being higher in calls produced by the tagged whale (Figure 5). The observed difference in RLs between tagged-whale calls and nontagged-whale calls was $7 \mathrm{~dB}$ (RMS re $1 \mu \mathrm{Pa}$ ), and we rejected the null hypothesis that RLs were the same in both conditions (rotation test, $p<0.001$ ). There was also a significant difference between SNRs of tagged whale and non-tagged-whale calls of $8 \mathrm{~dB}$ (rotation test, $p<0.001$ ). However, a large amount of overlap was still present in the distribution of values between the two conditions.

\section{Discussion}

\section{General calling behavior and comparison with other species}

The advent of animal-borne biologging devices and miniaturized technology including high-sample rate accelerometers has allowed us to compile this first description of fine-scale movement and calling behavior of tagged fin whales. Until now, our understanding of baleen whale calling behavior was based on broad interpretations from 

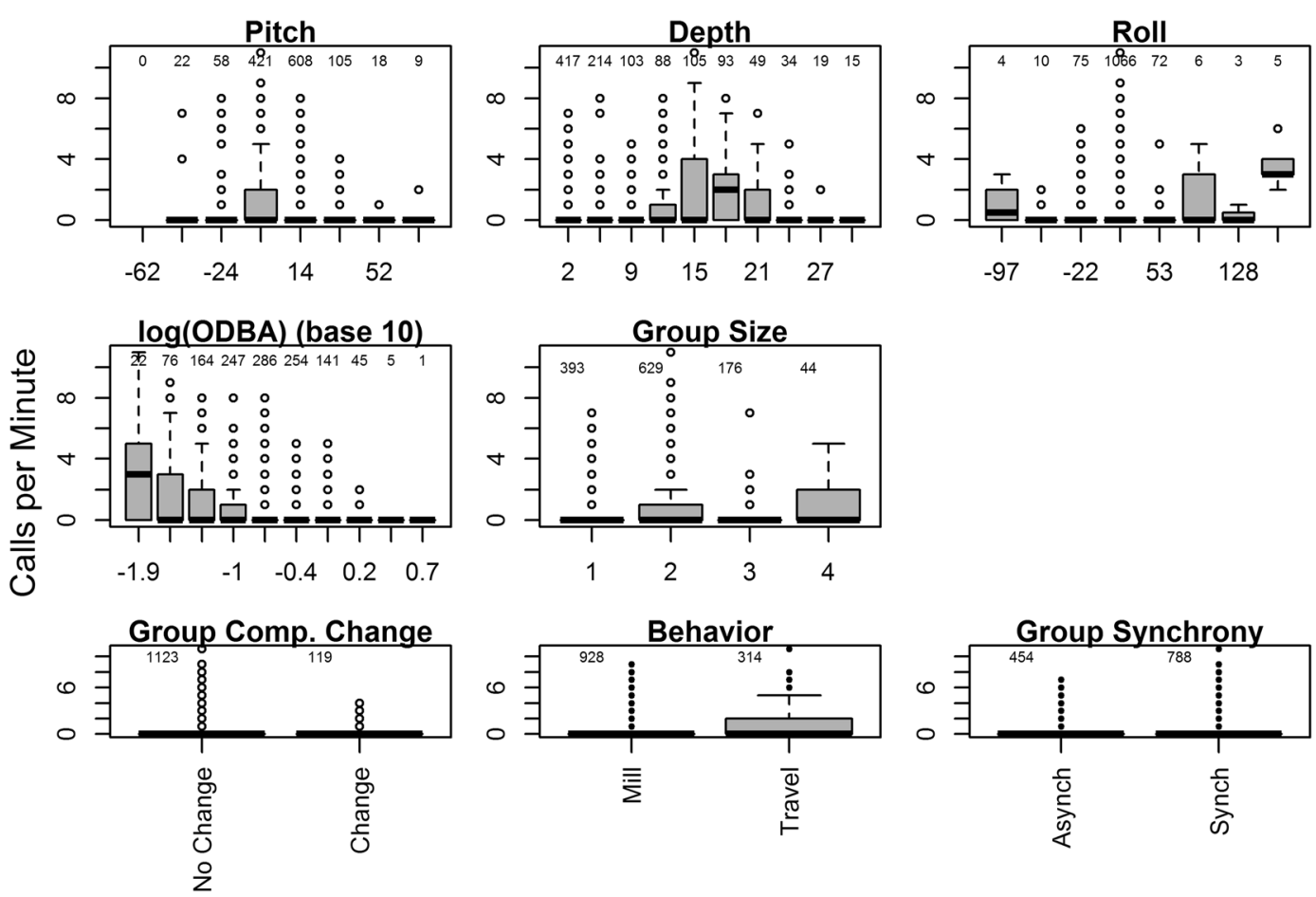

Figure $3 \mathrm{GEE}$ model dataset. Fin whale call data and covariates dataset for call rate modeling (only calls produced by the tagged whales). For the figures for tag-based covariates, data have been binned so that changes in call rates over the range of the tag-based covariate are more obvious. Numbers near the top of each plot indicate the number of data points in each bin.

passive acoustic data, generalizations from tag data based on assumptions, or limited to behavior of single individuals followed by observers. These precautions were necessary to avoid ambiguity about which animal in a group was producing a call. Our analyses showed that fin whales exhibited shallow, relatively longer duration dive patterns during calling bouts, and statistical modeling additionally predicted little body movement, downward pitch, and a trend toward animals that showed directed travel at the surface. The confidence intervals on the model predictions were large, because our dataset was relatively small and our analysis probably did not include all the factors contributing to elevated calling rates. However, the variables that were identified were consistent with previous reports of calling fin whale behavior from passive acoustic data, as well as descriptions of calling from other baleen whale species.

In their detailed description of fin whale calls, Watkins et al. [10] reported that whales producing $20 \mathrm{~Hz}$ signals were located at approximately $50 \mathrm{~m}$ depth, and when tracked at the surface, swam slowly and with little overall body movement (such as vigorous fluking). Though the consistency in depth was based only on extrapolations from differences in sound arrival times on different hydrophones and phase reversals from reflections during propagation, our description of calling fin whale behavior based on tag data in Southern California is generally similar. Animals were shallower (approximately $15 \mathrm{~m}$, although this could be an underestimate because depth measurements were a mean in a 1-min time bin rather than taken at the exact time of the call), but ODBA was low, indicating little movement. Traveling behavior is also consistent with PAM studies that have tracked individuals [9] (animals exhibiting slow, directed travel can still show low overall ODBA values).

Application of this behavioral profile of a calling animal may help surface-based visual observers identify callers, recognizing the limitations of the sample used to generate this study's results. In addition, factors that impact sighting rates for systematic visual surveys include group size, surfacing rate, and surfacing behavior. Our results indicate that calling fin whales could be more difficult to see since they may surface less frequently, move away from their last surfacing position (and so may be more difficult to track), and maintain a low profile in the water without a very high arch since they are not diving deeply.

The behavior of calling fin whales also has similarities to other baleen whales. Tagged blue whales were found to produce calls at depths between 10 and $30 \mathrm{~m}[15,21]$, and singing humpback whales are often found stationary 

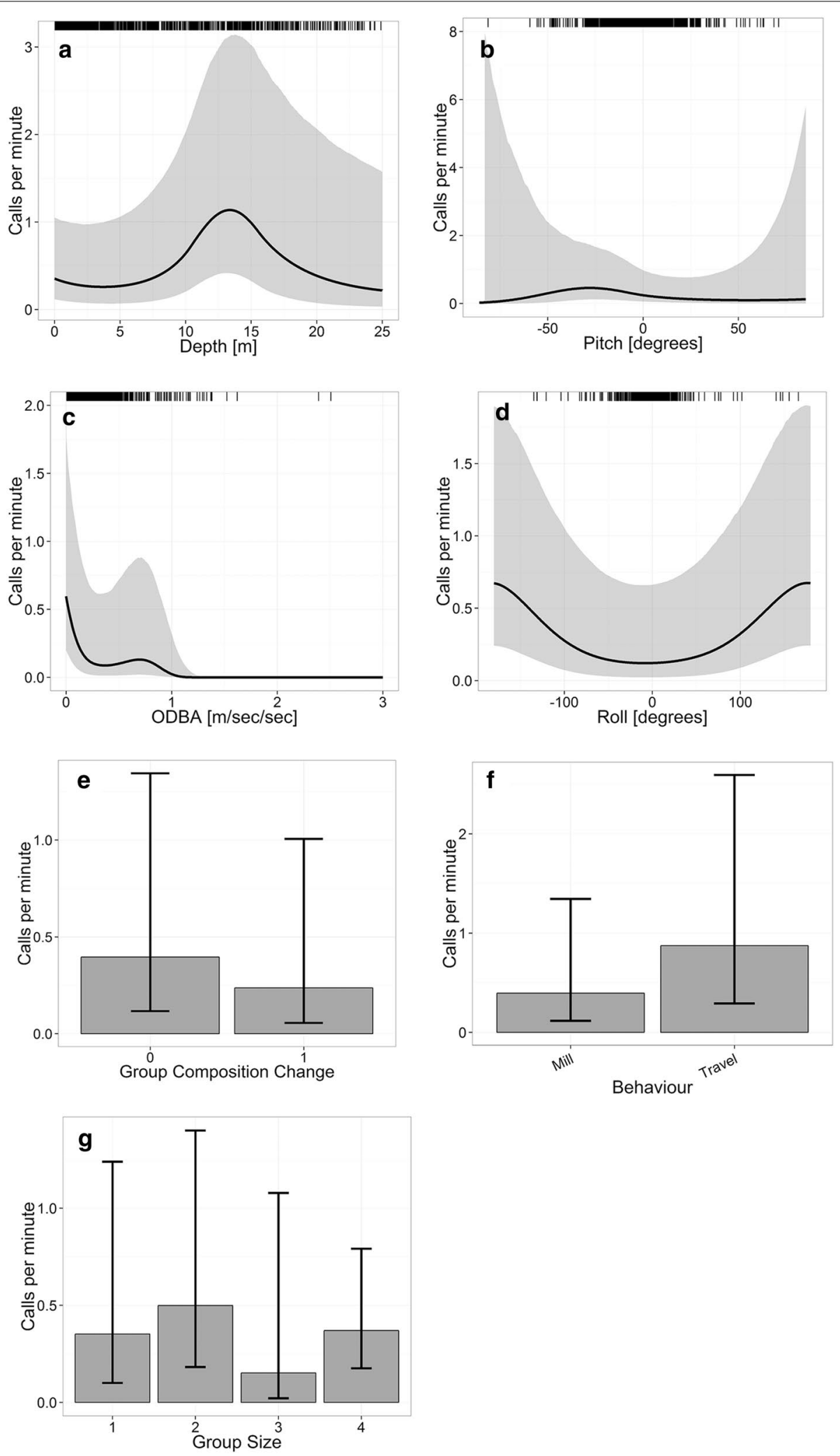
(See figure on previous page).

Figure 4 GEE model results. Predicted call rates from the GEE model as a function of caller depth (a), pitch (b), ODBA (c), roll (d), group composition change $(\mathbf{e})$, surface movement $(\mathbf{f})$, and group size $(\mathbf{g})$. Solid lines show predictions from the best-fitting model, with shaded areas indicating $95 \%$ confidence intervals from a parametric bootstrap. To make these predictions, other predictors were fixed at the values most common in the data: group size 1, no group composition change, behavior Mill, depth 5, ODBA 0.1, roll 0, and pitch - 29. All results shown are for calls detected on both accelerometers and acoustic record. (Note, we did not have enough data to make precise predictions for higher ODBA or extreme pitch and roll values, which were rarely or never observed in the dataset. Rug plots along the top of the tag data figure panels show locations where data points existed.).

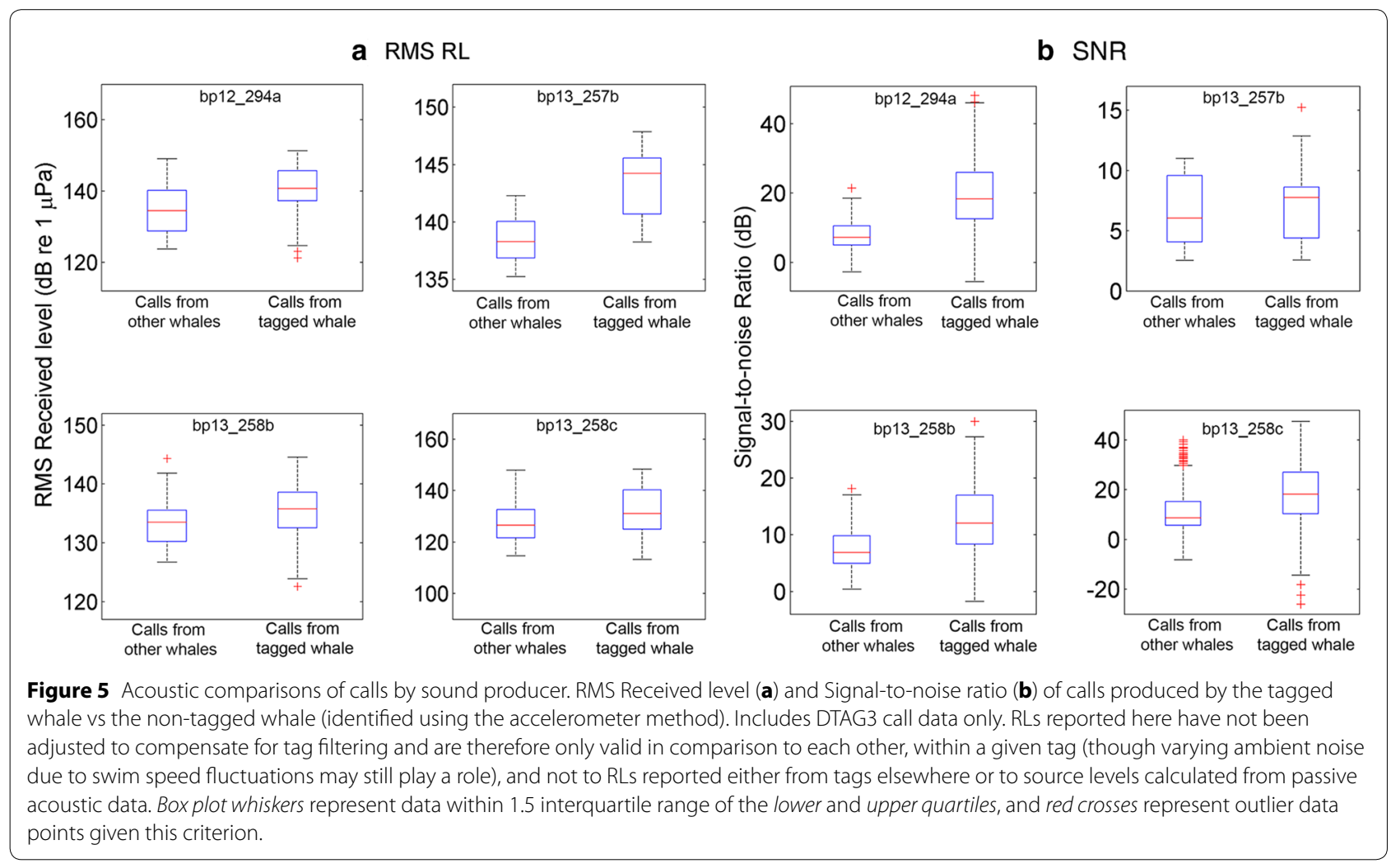

at approximately $20 \mathrm{~m}$, pitched slightly downward [6], similar to the fin whales in this study. It is possible that the similar depths, posture, and lack of large body movements among these large whales suggest either a physiological (based on the whales' sound production mechanism) or physical (based on areas of best sound propagation) parameter that allows animals to optimize their ability to communicate.

\section{Anatomical or physical/acoustic explanations for calling behavior}

Aroyan et al. [41] proposed a model for blue whale calling that was based on anatomy. Given a monopole sound source with no air escaping during sound production, expansion of the laryngeal sac was the mechanism suggested for sound production. They predicted that calling should be shallow, at depths less than $220 \mathrm{~m}$, and average depths as shallow as $30 \mathrm{~m}$. They also predicted that calling whales should require a depth change during individual call production to supplement the muscular effort to drive the pneumatic source, or to maintain the inflation of the laryngeal air sac. Oleson et al. [21] did not observe depth changes during calls in their tagged blue whale dataset, but did record callers at depths consistent with the predictions of Aroyan et al. (20-30 m). We similarly did not observe changes in depth over the course of each call, although fin whale calls are much shorter in duration than blue whale calls, so such behavior would be difficult to achieve.

Oleson et al. also speculated that these are the depths where blue whales are close to neutrally buoyant, and, perhaps more important, that signal strength would be optimally increased (up to $6 \mathrm{~dB}$ ) by surface reflection at these shallow depths. These postulated benefits gained from shallow water sound propagation in the case of blue whales could also be driving the sound production 
depths (10-15 m) of fin whales in this area. In our study area of Southern California, $20-30 \mathrm{~m}$ is a typical depth of the relatively warm surface layer, below which there is usually a sharp gradient in the pycnocline. This strong density difference is the location of significant changes in sound speed gradients as well as the right depth to get a Lloyd's mirror surface reflection enhancement [42], and would be easily detectable from a buoyancy perspective. Though surface mixing could create a sonic layer that traps higher frequencies, making near-surface sound propagation more efficient, whether or how exactly lowfrequency fin whales gain advantage in communication from these acoustic conditions is still unknown.

We can speculate that the downward-facing body orientation combined with sound production anatomy could help with horizontal propagation [43], as could particular propagation paths in the area, especially since tagged whales that received calls were often at similar depths to callers during sound production. In addition, if calling requires a large air volume in the lungs to drive pneumatic sound production, or a large air sac volume to maintain the appropriate frequency, then calling at deeper depths may be limited by reduction in air volume due to increasing ambient pressure at depth, and/or there may be a greater physiological effort to call at greater depths [43]. These factors may also contribute to whales using shallower calling depths.

\section{Accelerometer method vs. call acoustic parameters}

Though differences we found in call levels and SNRs between calls produced by the tagged animal and other fin whales in the area were significantly different, the difference was not large in magnitude. This is likely due to several factors. In particular, any body movement or swimming by the tagged animal will increase accelerometer noise and flow noise, thereby masking recordings of less intense calls that are being received from more distant animals. Thus, it is possible that most of the nontagged whale calls were produced by conspecifics at relatively short range (note, for example, the small sample size of non-tagged whale calls for bp13_257b, which may have increased variability in acoustic level measurements). In addition, overlap between the two datasets was substantial, and many calls identified to have been produced by conspecifics in the vicinity had levels and SNRs as high as or higher than some calls identified from tagged individuals. Readers should also keep in mind that accelerometer signals may be amplified by actual tissue vibration from sound production, making near-field particle velocity extrapolations less comparable with acoustic levels (refer to the appendix of [25] for further discussion on these issues). In general, the variability in acoustic properties of baleen whale sounds suggests that level-based discrimination should only be used with caution and with full understanding of its inherent assumptions, and research should continue to test methods for identifying individual callers in various situations.

\section{Possible responses to disturbance}

Regardless of the reasons for preferred calling depths and body orientation, these descriptions of fine-scale calling behavior give an important baseline for further studies of effects of disturbance from anthropogenic sources on calling animals. Watkins et al. [10] noted that "gaps" (quiet periods between 20 and $120 \mathrm{~min}$ during calling bouts) occurred at irregular times, sometimes at the approach of another fin whale, but also immediately corresponding to the close passage of a ship or the sound of a propeller cavitation starting up the area. Fin whales have also been shown to respond through changes in swimming behavior [44], but not in calling behavior [9], to the sound of earthquake noise in the ocean. It is clear that systematic experiments on fin whale responses to anthropogenic sound disturbance are needed. Our dataset was not large enough to address these questions, but such research is currently underway, and the baseline calling behavior reported here is a valuable standard against which calling behavior during and after potential disturbance can be compared in the future.

\section{Conclusions}

We identified several tag and surface behavioral state variables that influence call rates, including dive depth, body orientation and movement, and surface travel. Although the uncertainty associated with model parameter estimates and model predictions was high, this is the first quantification of the posture and depths at which fin whales are more likely to call, and how focal follow data relates to calling behavior. Our ability to identify the calling animal within our dataset resulted in quantitative analysis of the strong dependence of call rate on behavior. This analysis illustrates the need for caution in applying universal call rates to produce density estimates from PAM data if behavioral context differs between the call rate and PAM recordings. Further, our recordings were not long enough to accurately characterize silent periods or bout durations within calling animals, as calling (and silent) bouts sometimes appeared to extend beyond the length of the tag deployment. However, the percentage of calling animals and the number of calls produced during recording periods should help standardize interpretations of call detections in passive acoustic recordings. Future work with larger datasets (potentially including longer-term accelerometer tags to study call production over days or weeks) and including additional behavioral or environmental metrics will be required to accurately predict call rates in all situations. 
In addition, these baseline results will be critical in the assessment of fin whale response to sound exposure experiments. For fin whales, which can range over areas as large as ocean basins and that do not often travel in big groups of conspecifics, acoustic communication is critical. Increasing levels of ocean noise, especially from anthropogenic sources, underscore the importance of evaluating the sensitivity of this species to changes in local sound levels. Surface swimming behavior, dive depths, body orientation, and call rates of individuals subjected to experimental sound exposure can be compared during further research to behavior of animals in this study to quantify the type and severity of response to anthropogenic disturbance.

\section{Additional files}

Additional file 1: Acoustic audit file listing the calls that were manually identified in the acoustic record for tagged whale bp12_294a. The whale name signifies the species name, Balaenoptera physalus (bp), the two digit year of deployment, the three digit Julian day of deployment, and a letter representing the successive number deployment for that day. The file has three columns: time cue of the call in seconds since deployment; duration of the call in seconds; and a label indicating whether the call was produced by the tagged whale (' 1 ') or a different whale (' 0 ').

Additional file 2: Acoustic audit file listing the calls that were manually identified in the acoustic record for tagged whale bp13_257b. The whale name signifies the species name, Balaenoptera physalus (bp), the two digit year of deployment, the three digit Julian day of deployment, and a letter representing the successive number deployment for that day. The file has three columns: time cue of the call in seconds since deployment; duration of the call in seconds; and a label indicating whether the call was produced by the tagged whale (' 1 ') or a different whale (' 0 ').

Additional file 3: Acoustic audit file listing the calls that were manually identified in the acoustic record for tagged whale bp13_258b. The whale name signifies the species name, Balaenoptera physalus (bp), the two digit year of deployment, the three digit Julian day of deployment, and a letter representing the successive number deployment for that day. The file has three columns: time cue of the call in seconds since deployment; duration of the call in seconds; and a label indicating whether the call was produced by the tagged whale (' 1 ') or a different whale (' 0 ').

Additional file 4: Acoustic audit file listing the calls that were manually identified in the acoustic record for tagged whale bp13_258c. The whale name signifies the species name, Balaenoptera physalus (bp), the two digit year of deployment, the three digit Julian day of deployment, and a letter representing the successive number deployment for that day. The file has three columns: time cue of the call in seconds since deployment; duration of the call in seconds; and a label indicating whether the call was produced by the tagged whale $\left({ }^{\prime} 1\right.$ ') or a different whale $\left({ }^{\prime} 0\right.$ ').

\section{Authors' contributions}

AKS organized and performed data analysis and wrote the paper. SDR performed statistical and data analysis and helped write the paper. EAF and JAG performed data analysis. All authors were involved with fieldwork and edited the manuscript draft. All authors read and approved the final manuscript.

\footnotetext{
Author details

${ }^{1}$ Vertebrate Ecology Laboratory, Moss Landing Marine Laboratories, Moss Landing, CA, USA. ${ }^{2}$ Centre for Research into Ecological and Environmental Modelling, School of Mathematics and Statistics, University of St Andrews, The Observatory, Buchanan Gardens, St Andrews, Fife KY16 9LZ, Scotland, UK. ${ }^{3}$ Mathematics and Statistics Department, Calvin College, 3201 Burton
}

SE, Grand Rapids, MI 49546, USA. ${ }^{4}$ Cascadia Research Collective, 218 1/2 W. Fourth Ave., Olympia, WA 98501, USA. ${ }^{5}$ Ocean Acoustics Laboratory, Department of Oceanography, Naval Postgraduate School, Monterey, CA, USA. ${ }^{6}$ Naval Undersea Warfare Center, Newport, RI, USA. ${ }^{7}$ Department of Fisheries and Wildlife, Marine Mammal Institute, Hatfield Marine Science Center, Oregon State University, Newport, OR 97365, USA. ${ }^{8}$ Southall Environmental Associates, Aptos, CA 95003, USA. ${ }^{9}$ Sea Mammal Research Unit, Scottish Oceans Institute, School of Biology, University of St Andrews, East Sands, St Andrews KY16 8LB, Scotland, UK. ${ }^{10}$ Department of Biology, Hopkins Marine Station, Stanford University, 120 Ocean View Blvd., Pacific Grove, CA 93950, USA.

\section{Acknowledgements}

Many thanks are due to the entire SOCAL BRS team, particularly chief scientist Brandon Southall, as well as the RN Truth crew. Research was supported by the US Navy Chief of Naval Operations, Environmental Readiness Program and later the Living Marine Resources Program (SOCAL BRS project), and the US Office of Naval Research via grants to the MOCHA and SOCAL BRS projects. PLT received funding from the MASTS pooling initiative (the Marine Alliance for Science and Technology for Scotland) and their support is gratefully acknowledged. MASTS is funded by the Scottish Funding Council (grant reference HR09011) and contributing institutions. This publication also results from research supported by the Naval Postgraduate School, Assistance Agreement No. N00244-14-2-0002. Experiments were carried out under NMFS permit 14534 (B. Southall, principal investigator) and 16111 (J. Calambokidis, principal investigator)

\section{Compliance with ethical guidelines}

\section{Competing interests}

The authors declare no competing interests.

Received: 31 January 2015 Accepted: 9 July 2015

Published online: 03 August 2015

\section{References}

1. Catchpole CK (1987) Bird song, sexual selection and female choice. Trends Ecol Evol 2(4):94-97

2. Seyfarth RM, Cheney DL, Marler P (1980) Monkey responses to 3 different alarm calls-evidence of predator classification and semantic communication. Science 210(4471):801-803

3. Griffin DR, Webster FA, Michael CR (1960) The echolocation of flying insects by bats. Anim Behav 8(3-4):141-154

4. Au WWL (1993) The sonar of dolphins. Springer, New York

5. Payne RS, McVay S (1971) Songs of humpback whales. Science 173(3997):585-597

6. Tyack P (1982) Humpback whales respond to sounds of their neighbors. PhD Thesis, Rockefeller University, New York

7. Richardson WJ, Greene CR, Malme Cl, Thomson DH (1995) Marine mammals and noise. Academic Press, San Diego

8. Sirovic A, Hildebrand JA, Wiggins SM (2007) Blue and fin whale call source levels and propagation range in the Southern Ocean. J Acoust Soc Am 122(2):1208-1215

9. McDonald MA, Hildebrand J, Webb SC (1995) Blue and fin whales observed on a seafloor array in the Northeast Pacific. J Acoust Soc Am 98:1-10

10. Watkins WA, Tyack P, Moore KE, Bird JE (1987) The 20-Hz signals of finback whales (Balaenoptera physalus). J Acoust Soc Am 82(6):1901-1912

11. Watkins WA, George JE, Daher MA, Mullin KD, Martn DL, Haga SH et al (2000) Whale call data for the North Pacific, November 1995 through July 1999: occurrence of calling whales and source locations from SOSUS and other acoustic systems. WHOI Tech Rep 2000:2002

12. Sirovic A, Williams L, Kerosky S, Wiggins S, Hildebrand J (2013) Temporal separation of two fin whale call types across the eastern North Pacific. Mar Biol 160:47-57

13. Oleson EM, Sirovic A, Bayless A, Hildebrand JA (2014) Synchronous seasonal change in fin whale song in the North Pacific. PLoS One 9(12):e115678. doi:10.1371/journal.pone.0115678 
14. Marques T, Thomas L, Martin S, Mellinger D, Ward J, Tyack P et al (2013) Estimating animal population density using passive acoustics. Biol Rev. doi:10.1111/brv.12001

15. Thode AM, D'Spain GL, Kuperman WA (2000) Matched-field processing, geoacoustic inversion, and source signature recovery of blue whale vocalizations. J Acoust Soc Am 107(3):1286-1300

16. McDonald MA, Fox CG (1999) Passive acoustic methods applied to fin whale population density estimation. J Acoust Soc Am 105(5):2643-2651

17. Stimpert AK, Wiley DN, Au WWL, Johnson MP, Arsenault R (2007) 'Megapclicks': acoustic click trains and buzzes produced during night-time foraging of humpback whales (Megaptera novaeangliae). Biol Lett 3(5):467-470

18. Parks SE, Cusano DA, Stimpert AK, Weinrich MT, Friedlaender AS, Wiley DN (2014) Evidence for acoustic communication among bottom foraging humpback whales. Sci Rep 4:7508. doi:10.1038/srep07508

19. Parks SE, Searby A, Celerier A, Johnson M, Nowacek DP, Tyack P (2011) Sound production behavior of individual North Atlantic right whales: implications for passive acoustic monitoring. Endanger Spec Res. 15:63-76

20. Risch D, Gales NJ, Gedamke J, Kindermann L, Nowacek DP, Read AJ et al (2014) Mysterious bio-duck sound attributed to the Antarctic minke whale (Balaenoptera bonaerensis). Biol Lett 10:20140175. doi:10.1098/ rsbl.2014.0175

21. Oleson EM, Calambokidis J, Burgess WC, McDonald MA, LeDuc CA, Hildebrand JA (2007) Behavioral context of call production by eastern North Pacific blue whales. Mar Ecol Prog Ser 330:269-284

22. Calambokidis J, Schorr GS, Steiger GH, Francis J, Bakhtiari M, Marshall $\mathrm{G}$ et al (2007) Insights into the underwater diving, feeding, and calling behavior of blue whales from a suction-cup-attached video-imaging tag (CRITTERCAM). Mar Technol Soc J 41(4):19-29

23. Au WWL, Pack AA, Lammers MO, Herman LM, Deakos MH, Andrews K (2006) Acoustic properties of humpback whale songs. J Acoust Soc Am 120(2):1103-1110

24. Johnson M, Aguilar de Soto N, Madsen PT (2009) Studying the behaviour and sensory ecology of marine mammals using acoustic recording tags: a review. Mar Ecol Prog Ser 395:55-73

25. Goldbogen JA, Stimpert AK, DeRuiter SL, Calambokidis J, Friedlaender AS, Schorr GS et al (2014) Using accelerometers to determine the calling behavior of tagged baleen whales. J Exp Biol 217:2449-2455. doi:10.1242/ jeb.103259

26. Thompson PO, Findley LT, Vidal O (1992) 20-Hz pulses and other vocalizations of fin whales, Balaenoptera physalus, in the Gulf of California, Mexico. J Acoust Soc Am 92(6):3051-3057

27. Watkins WA (1981) Activities and underwater sounds of fin whales. Sci Rep Whales Res Inst 33:83-117

28. Edds PL (1988) Characteristics of finback Balaenoptera physalus vocalizations in the St. Lawrence estuary. Bioacoustics 1:131-149
29. Delarue J (2004) Northwest Atlantic fin whale vocalizations: geographic variations and implications for stock assessments. MS Thesis, Hawaii Pacific University

30. Edds-Walton P (1997) Acoustic communication signals of mysticete whales. Bioacoustics 8:47-60

31. Croll DA, Clark CW, Acevedo A, Tershy B, Flores S, Gedamke J et al (2002) Only male fin whales sing loud songs. Nature 417:809

32. Southall B, Moretti DJ, Abraham B, Calambokidis J, Deruiter S, Tyack P (2012) Marine mammal behavioral response studies in Southern California: advances in technology and experimental methods. Mar Technol Soc J 46(4):48-59

33. Johnson MP, Tyack PL (2003) A digital acoustic recording tag for measuring the response of wild marine mammals to sound. IEEE J Ocean Eng 28(1):3-12

34. Shepard ELC, Wilson R, Halsey LG, Quintana F, Gomez Laich A, Gleiss AC et al (2008) Derivation of body motion via appropriate smoothing of acceleration data. Aquat Biol 4:235-241

35. Team RC (2014) R: a language and environment for statistical computing. R Foundation for Statistical Computing, Vienna

36. LAS S-H, CS O, Mackenzie M, Walker C, Rexstad E (2013) User guide for the MRSea Package: Statistical modelling of bird and cetacean distributions in offshore renewables development areas. University of St Andrews, Contract with Marine Scotland: SB9 (CR/2012/05)

37. Hojsgaard S, Halekoh U, Yan J (2006) The R Package geepack for Generalized Estimating Equations. J Stat Softw 15(2):1-11

38. Walker C, Mackenzie M, Donovan C, O-Sullivan M (2011) SALSA: a spatially adaptive local smoothing algorithm. J Stat Comput Simul 81:179-191. doi:10.1080/00949650903229041

39. Hardin J, Hilbe J (2012) Generalised Estimating Equations, 2nd edn. CRC Press, Boca Raton

40. DeRuiter SL, Solow AR (2008) A rotation test for behavioural point-process data. Anim Behav 76:1429-1434

41. Aroyan J, McDonald MA, Webb SC, Hildebrand J, CLark D, Laitman JT et al (2000) Acoustic models of sound production and propagation. In: Au WWL, Popper AN, Fay RR (eds) Hearing by Whales and Dolphins. Springer, New York, pp 409-469

42. Urick R (1983) Principles of Underwater Sound

43. Reidenberg JS, Laitman JT (2007) Discovery of a low frequency sound source in mysticeti (Baleen whales): anatomical establishment of a vocal fold homolog. Anat Rec Adv Integr Anat Evol Biol 290(6):745-759

44. Gallo-Reynoso J-P, Edgido-Villarreal J, Martinez-Villalba L (2011) Reaction of fin whales Balaenoptera physalus to an earthquake. Bioacoustics 20:317-330

\section{Submit your next manuscript to BioMed Central and take full advantage of:}

- Convenient online submission

- Thorough peer review

- No space constraints or color figure charges

- Immediate publication on acceptance

- Inclusion in PubMed, CAS, Scopus and Google Scholar

- Research which is freely available for redistribution

Submit your manuscript at 